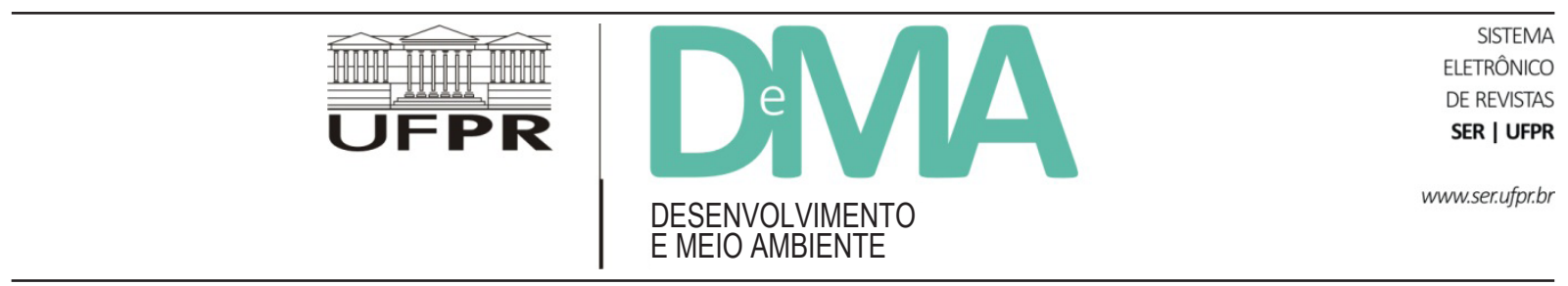

\title{
Análise da Política Nacional de Resíduos Sólidos e a indústria do petróleo
}

\section{Analysis of the National Solid Waste Policy and the Oil Industry}

\author{
Carlos José Saldanha MACHADO ${ }^{1,2}$, Beatriz Martins TEIXEIRA ${ }^{3 *}$, Rodrigo Machado VILANI ${ }^{4,5}$ \\ ${ }^{1}$ Fundação Oswaldo Cruz, Rio de Janeiro, RJ, Brasil. \\ ${ }^{2}$ Programa de Pós-Graduação Multidisciplinar de Meio Ambiente (PPG-MA), Universidade do Estado do Rio de Janeiro (UERJ), Rio de \\ Janeiro, RJ, Brasil. \\ ${ }^{3}$ Centro Federal de Educação Tecnológica Celso Suckow da Fonseca (CEFET), Rio de Janeiro, RJ, Brasil. \\ ${ }^{4}$ Universidade Federal do Estado do Rio de Janeiro (UNIRIO), Rio de Janeiro, RJ, Brasil. \\ ${ }^{5}$ Mestrado Profissional em Planejamento Regional e Gestão da Cidade, Universidade Cândido Mendes, Campos dos Goytacazes, RJ, Brasil. \\ *E-mail de contato: beatrizmartei@gmail.com
}

Artigo recebido em 9 de fevereiro de 2015, versão final aceita em 17 de novembro de 2015.

RESUMO: $\quad$ A Constituição Federal Brasileira de 1988 garantiu a todos um ambiente ecologicamente equilibrado e sadio. E, para tanto, é necessário que quaisquer atividades humanas, principalmente as industriais, que interfiram no meio ambiente sejam controladas. Os resíduos sólidos configuram-se como um dos principais componentes dos impactos ambientais produzidos pelas atividades industriais. Por esse motivo, eles necessitam ser monitorados e controlados ao longo de sua produção. A indústria do petróleo é classificada como altamente poluente e uma das razões para essa categorização é a geração dos seus resíduos sólidos. O presente trabalho tem como objetivo realizar uma análise da Lei 12.305/10, que instituiu a Política Nacional de Resíduos Sólidos (PNRS), e verificar a adequação da indústria do petróleo quanto ao seu conteúdo. A metodologia utilizada foi a de revisão bibliográfica para um levantamento do arcabouço jurídico ambiental cabível nesse tema e, posteriormente, as legislações ambientais aplicadas ao caso foram comparadas e analisadas quanto à sua coerência e legalidade; por fim, a partir dos dados explicitados numa Nota Técnica do IBAMA quanto aos resíduos sólidos produzidos pela indústria do petróleo, foram apontadas omissões e inconsistências perante o atual modelo de desenvolvimento sustentável adotado pela $\mathrm{CF} / 88$. Sendo assim, percebe-se que é necessário um alinhamento entre as normas brasileiras e uma melhor adequação da indústria do petróleo quanto aos resíduos sólidos produzidos nessa atividade industrial.

Palavras-chave: desenvolvimento sustentável; resíduos sólidos; indústria do petróleo.

ABSTRACT: The Brazilian Constitution of 1988 guaranteed everyone a healthy and ecologically balanced environment. And for this it is necessary that any human activity, especially industrial, that interfere in the environment 
be controlled. Solid waste configures itself as a major component of the environmental impacts produced by industrial activities. For this reason, they need to be monitored and controlled throughout its production. The oil industry is classified as highly polluting, and one reason for this categorization is the generation of solid waste. This study aims at conducting an analysis of the National Solid Waste Policy in Brazil, published in 2010 , and the adequacy of the oil industry as to its content. The methodology used was a literature review for a survey of the environmental legal framework applicable in this subject, and afterward environmental laws applied to the case were compared and analyzed for consistency and legality; finally, from the data explained in IBAMA's Technical Note regarding the solid waste produced by the oil industry, omissions and inconsistencies were pointed to the current model of sustainable development adopted by the $\mathrm{CF} / 88$. Thus, we can see that an alignment is required within Brazilian standards, as well as meeting the requirements of the oil industry on the solid waste produced in this industrial activity.

Keywords: sustainable development; solid waste; oil industry.

\section{Introdução}

Os desafios ambientais, climáticos, sociais e econômicos deste início de século colocam sociedade, governos, empresas e cientistas diante de inúmeros questionamentos a respeito das alternativas para um modelo de desenvolvimento compatível com a capacidade de suporte do planeta e com a perpetuidade da qualidade de vida da população (Machado, 2014). São inúmeros acontecimentos que vêm ocorrendo e que incitam a revisão das formas de produção, dos meios de subsistência e de como a humanidade se relaciona com o meio ambiente. Durante muitos anos, as sociedades conviveram com o ideal do crescimento, que sugere a infinitude dos recursos naturais e que foi construído como uma ideia positiva, pautado pelo imediatismo e por aspectos meramente quantitativos. Entretanto, esse modelo baseado na "cultura de dilapidação do capital natural como um dos valores da economia de mercado" (Machado, C. J. S., 2012, p. 13) vem ocasionando uma série de fatores, interdependentes, que desencadeiam graves crises, a exemplo das mudanças climáticas e do aquecimento global, da perda de biodiversidade e do aumento de todas as formas de poluição, entre muitos outros problemas.

Diante desse cenário, o arcabouço jurídico-institucional brasileiro ampliou, ao longo dos últimos trinta anos, o rol de atividades e setores regulamentados, de parâmetros e padrões de controle e respectivos instrumentos de coerção com a promulgação de inúmeras leis federais instituidoras de políticas públicas ambientais.
Desde a publicação da Lei 6.938/81, que instituiu a Política Nacional de Meio Ambiente, e da Constituição Federal de 1988 que, em seu artigo 225, estabeleceu o direito ao meio ambiente ecologicamente equilibrado para as presentes e futuras gerações como um direito fundamental, outros diplomas legais que envolvem a temática ambiental começaram a surgir, merecendo destaque as Políticas Nacionais: de Recursos Hídricos (Lei 9.433/97), Energética (Lei 9.478/97), de Educação Ambiental (Lei 9.795/99), de Biodiversidade (Decreto 4.339/02), sobre Mudança do Clima (Lei 12.187/09) e dos Resíduos Sólidos (Lei 12.305/10). Ainda que o conteúdo dessas normas demonstre um avanço no processo de construção de marcos regulatórios, percebe-se que a política ambiental brasileira não foi estruturada a partir de uma visão holística, como seria desejável, mas, sim, de forma setorizada (Machado et al., 2012, p. 180).

Indo ao encontro de uma perspectiva holística na formalização de uma política pública ambiental (Machado, 2014), o presente trabalho analisa a Lei ${ }^{\circ} 12.305 / 10$, que instituiu a Política Nacional de Resíduos Sólidos, doravante PNRS. A PNRS se propôs a apresentar uma base de princípios, objetivos e instrumentos visando estabelecer diretrizes quanto à gestão integrada, ao gerenciamento de resíduos sólidos, às responsabilidades dos geradores e do poder público e aos instrumentos econômicos aplicáveis. No texto da lei há a intenção de regular toda a extensão da produção dos resíduos sólidos, desde a extração da matéria-prima até o consumidor final, estabelecendo, inclusive, responsabilidades compartilhadas. Contudo, como será demonstrado, a PNRS não 
conseguiu se distanciar da consagrada visão setorizada de políticas públicas, pois deu grande ênfase à produção dos resíduos urbanos e um tímido detalhamento sobre a regulamentação da produção dos resíduos industriais e perigosos.

O recorte proposto - indústria petrolífera justifica-se pela sua importância econômica no cenário nacional, pelo potencial poluidor da atividade e pela falta de regulamentação específica para os resíduos sólidos. A expansão do setor é outro elemento de relevância para a discussão proposta. De acordo com a ANP (2014, p. 11), em dezembro de 2014 estavam em fase de produção 309 campos, com uma produção total de 2.497 .231 barris por dia. Conforme previsões de Tolmasquim (2012, p. 256), no ano de 2020 a produção de petróleo do Brasil deve atingir cerca de seis milhões de barris por dia.

A expansão da indústria petrolífera requer uma atuação integrada da administração pública, especialmente dos órgãos das áreas de energia, petróleo e meio ambiente, para a revisão e atualização dos instrumentos de fiscalização e controle e das normas de regulamentação dessa atividade causadora de significativos impactos ambientais. Especificamente, os resíduos sólidos perigosos gerados pela exploração e produção de petróleo e gás natural demandam o estabelecimento de padrões de qualidade ambiental. Isso porque uma das principais fontes de poluição desse setor da economia nacional é a produção de resíduos sólidos perigosos decorrentes das atividades de perfuração, produção, transporte, armazenamento e refino. A cadeia de produção de petróleo compreende também a produção de derivados de petróleo, utilizados em larga escala, e a geração de resíduos próprios, tais como: produtos asfálticos, querosenes, solventes, óleos combustíveis e lubrificantes, entre outros. Segundo Jacques e colaboradores (2007, p. 1192), na composição de seus produtos são encontrados "os hidrocarbonetos aromáticos policíclicos, [...] compostos mutagênicos e carcinogênicos aos humanos e aos animais, que são introduzidos no ambiente em grandes quantidades, devido às atividades relacionadas à extração, ao transporte, ao refino, à transformação e à utilização do petróleo e de seus derivados". Um efeito negativo da exploração desse recurso natural não renovável sobre os solos e os ecossistemas deve-se ao fato de os microrganismos do solo, na grande maioria, não possuírem "a capacidade de degradá-los, resultando na sua acumulação no ambiente e na consequente contaminação dos ecossistemas" (Jacques et al., 2007, p. 1192). A indústria petrolífera também contribui, de forma significativa, na composição dos resíduos industriais. Esses resíduos, em alguns casos, são destinados de forma inadequada e entram em contato com o solo de vazadouros ou de aterros sanitários e industriais, causando "contaminação ambiental e humana por substâncias carcinogênicas" (Sisinno et al., 2003, p. 673).

A hipótese levantada é de que a lei $\mathrm{n}^{0} 12.305 / 10$ não conseguiu atingir eficazmente, com seus dispositivos, todos os tipos de atividades industriais, em especial a indústria do petróleo. Isso é de extrema relevância, por este setor específico da economia ser notadamente categorizado como potencialmente poluente, gerador de resíduos perigosos nas diversas fases de seu ciclo produtivo e pelas expectativas de expansão do setor prevista em razão dos novos investimentos para a produção da camada do pré-sal.

É preciso reconhecer, portanto, a complexidade que envolve a aplicação da PNRS na intrincada rede de beneficiamento, de prestadores de serviços e das empresas petrolíferas propriamente ditas e a periculosidade de seus resíduos para o ambiente e a saúde humana. Nesse sentido, o presente artigo tem por objetivo contribuir para o aprimoramento da Política Nacional de Resíduos Sólidos aplicada à indústria do petróleo de um país com extensão continental e diversidade econômica, sociocultural e ambiental, que engloba seis biomas - Amazônia, Cerrado, Mata Atlântica, Caatinga, Pantanal e Pampa -, 12 regiões hidrográficas e $7.367 \mathrm{~km}$ de costa se estendendo pelo Oceano Atlântico.

A opção metodológica foi a pesquisa quali-quantitativa. Foram analisados os textos das Leis Federais $\mathrm{n}^{\circ} 12.305 / 2010$ e $\mathrm{n}^{\circ}$ 9.966/00 e da Nota Técnica Ibama. A discussão dos textos adotou os princípios de Direito Ambiental e a harmonia do ordenamento jurídico como elementos de análise. Em razão da delimitação do objeto, procurou-se analisar a PNRS em sua harmonização com a política pública ambiental, no âmbito federal. Essa premissa (harmonia com o ordenamento jurídico) é fundante na sistemática jurídica, ou seja, a "coerência e harmonia interna de suas disposições, mas também a sua adequada inserção no sistema jurídico como um todo" 
(Mendes et al., 2002, p. 79). Dessa forma, a análise das normas, em especial da PNRS, se deu a partir da Constituição Federal e da Lei 6.938/81 (Política Nacional de Meio Ambiente). Ainda que haja produção científica sobre os temas isoladamente, são escassas as pesquisas específicas que relacionem a regulamentação pela PNRS da produção de resíduos perigosos da indústria petrolífera. Logo, para o embasamento teórico, foi consultada a literatura especializada em Direito Ambiental. A construção da lógica principiológica, ou seja, dos princípios de Direito Ambiental aplicáveis, permitiu a análise do contexto de aplicação da Lei n ${ }^{\circ}$ 12.305/2010. $\mathrm{O}$ contexto está relacionado às normas gerais em vigor, como a regulamentação do instrumento do licenciamento ambiental, e ao potencial danoso dos resíduos da indústria petrolífera, identificado na Nota Técnica Ibama. A avaliação da regulamentação da produção dos resíduos sólidos na indústria do petróleo foi, então, realizada com base nos princípios de Direito Ambiental, nos objetivos e princípios constitucionais e da Política Nacional de Meio Ambiente e no diagnóstico técnico dos resíduos realizado pelo Ibama. O distanciamento ou a aproximação do texto da PNRS destes elementos conduziu a discussão acerca da hipótese apresentada.

\section{Princípios estruturantes das políticas ambientais}

A Conferência de Estocolmo, realizada em 1972, é o marco dos debates multilaterais sobre a necessidade de se compatibilizar crescimento econômico, bem-estar e proteção ambiental. Fruto dessa preocupação, em 1987, é cunhada, por meio do Relatório Brundtland, a definição de desenvolvimento sustentável alicerçada sobre o equilíbrio entre as necessidades das presentes e futuras gerações (United Nations, 1987). Desenvolvimento sustentável, portanto, compreende um processo complexo e dinâmico que deve nortear as mudanças necessárias sobre as formas de produção, as políticas nacionais, o desenvolvimento científico e tecnológico, e o modo de organização social para garantir uma sadia qualidade de vida para as presentes e futuras gerações (Bucci, 2001, p. 60-61; Machado, 2014).
Na literatura sobre o tema são encontradas inúmeras críticas ao conceito, considerado amplo e vago (Farzin, 2002; Carneiro, 2005; Veiga, 2006; Lenzi, 2006), características que permitem sua apropriação segundo diferentes interesses e, assim, podendo ser entendido como um mecanismo de perpetuação do desenvolvimento econômico, pois se configura numa tentativa de compatibilizar a "continuação indefinida da acumulação capitalista e a reposição, também indefinida, de suas condições naturais de possibilidade" (Carneiro, 2005, p. 30). Entretanto, não obstante a importância desses questionamentos, nesse trabalho sustenta-se a relevância do estabelecimento de diretrizes de longo prazo para as políticas públicas como forma de aplicação de qualquer modelo de desenvolvimento que se proponha sustentável (Vilani \& Machado, 2010; Machado, 2014). Nesse sentido, destaca-se a leitura da Constituição Federal (CF/88) realizada por Machado \& Vilani (2010), na qual defendem que o desenvolvimento nacional proposto pelo legislador constituinte está assentado sobre o ideal de sustentabilidade, visto que congrega todas as variáveis do conceito proposto pelo Relatório Brundtland. Dessa forma, o desenvolvimento nacional sustentável, consoante a interpretação constitucional, exige a redução das desigualdades regionais e sociais, a instauração de uma ordem econômica que tenha por finalidade assegurar a todos existência digna em consonância com a preservação ambiental, a proteção ao direito ao meio ambiente ecologicamente equilibrado e a atenção aos direitos das gerações futuras. Mediante essa leitura, é possível reconhecer que o desenvolvimento nacional sustentável é um princípio basilar não apenas da Ordem Econômica, mas também da definição de políticas públicas, de maneira geral, e da regulamentação das atividades potencialmente poluidoras, em especial.

Em conjunto com o desenvolvimento sustentável, ainda existem outros princípios dentro do arcabouço jurídico ambiental brasileiro que completam essa estrutura regulatória. Assim, segundo Paulo Affonso Leme Machado (2012), configuram a base para a aplicação da PNRS os princípios da prevenção, da equidade intergeracional e do poluidor-pagador.

Para Paulo Affonso Leme Machado (2012, p. 25), o princípio da prevenção irá contribuir para o fortalecimento do desenvolvimento sustentável na medida 
em que busca prever a antecipação de condutas que provoquem danos ao meio ambiente e à saúde pública, pois a prevenção é aplicada aos impactos ambientais já conhecidos e que, portanto, possam ter estabelecido os nexos causais entre a conduta e o dano (Antunes, 2008, p. 45). Ademais, ressalta-se que a "prevenção não é estática" (Machado, 2010, p. 68) e sua materialização, dentro das exigências do licenciamento ambiental à implantação de aterros sanitários, por exemplo, deve acompanhar os avanços tecnológicos e científicos relacionados às novas classificações de periculosidade dos resíduos. Complementarmente, esse princípio se volta para a "prioridade que deve ser dada às medidas que evitem o nascimento de atentados ao ambiente, de molde a reduzir ou eliminar as causas de ações suscetíveis de alterar a sua qualidade" (Milaré, 2000, p. 102). Desse modo, são compreendidas como aplicação da prevenção na PNRS a implementação dos Planos, a existência dos mecanismos para a destinação e a disposição final ambientalmente adequada dos resíduos sólidos.

Por sua vez, o princípio da equidade intergeracional busca garantir para as presentes e futuras gerações o direito equânime ao meio ambiente sadio e à qualidade de vida. Esse princípio gera um dever transgeracional com vínculos obrigacionais no futuro, por meio do qual se estabelece que as atuais gerações receberam o patrimônio ambiental das gerações passadas, logo deverão deixar para as gerações futuras o ambiente em condições no mínimo iguais ou melhores do que as recebidas (Carvalho, 2008, p. 20-21).

Já o princípio do poluidor-pagador impõe-se, segundo a Política Nacional de Meio Ambiente, ao poluidor e ao predador, como obrigação de recuperar e/ou indenizar os danos causados. Milaré (2000, p. 100) e Derani (2001, p. 162) ressaltam que esse princípio encerra uma exigência de internalização dos custos externos da degradação ambiental causada pelos agentes econômicos. A equidade do princípio do poluidor-pagador consiste no não pagamento por parte daqueles que não usam ou não se beneficiaram do recurso ambiental frente aqueles que o usam (Machado, 2010).

Essas disposições deverão nortear a construção de qualquer proposta de política ambiental no Brasil, além de conferir para as políticas já existentes um novo horizonte de interpretação. Da mesma forma, deverão orientar os instrumentos de aplicação das políticas, a exemplo do licenciamento ambiental, detalhado na próxima seção.

\section{O licenciamento ambiental da indústria do petróleo}

Na década de 1980, acompanhando as discussões ambientais mundiais, o Brasil institui a Política Nacional de Meio Ambiente, marco legal do sistema de proteção ambiental brasileiro e que se configura como um "conjunto dos instrumentos legais, técnicos, científicos, políticos e econômicos destinados à promoção do desenvolvimento sustentado da sociedade e economia brasileiras" (Antunes, 2008, p. 104). Nesse sentido, foi promulgada uma série de objetivos, princípios e instrumentos, além de ser criado o Sistema Nacional de Meio Ambiente (Sisnama), que é um conjunto de órgãos governamentais que terão como principal objetivo efetivar a política ambiental brasileira. Como órgão executor da política ambiental na estrutura do Sistema Nacional está o Instituto Brasileiro do Meio Ambiente e dos Recursos Naturais Renováveis (Ibama). O licenciamento ambiental é um dos principais instrumentos de controle do estado sobre as atividades produtivas nacionais, um procedimento administrativo que tem o objetivo de avaliar, mediante concessão, ou não, de licença, as condições de localização, instalação, ampliação e operação de atividades de exploração dos recursos ambientais e que são consideradas efetiva ou potencialmente poluidoras, ou que possam causar degradação ambiental.

Pelo fato de as atividades da indústria do petróleo e gás serem consideradas altamente poluentes, necessitando de um procedimento de licenciamento específico - regulamentado no país por três resoluções do Conselho Nacional do Meio Ambiente ( ${ }^{\circ}$ s 237/97, 23/94, 350/04) e por uma portaria do Ibama $\left(\mathrm{n}^{\circ} 422 / 11\right)$-, as etapas produtivas desse setor industrial foram enquadradas em cinco tipos de licenças ambientais: (1) licença de pesquisa sísmica; (2) licença prévia para perfuração; (3) licença prévia de produção para pesquisa; (4) licença de instalação; (5) licença de operação. O licenciamento ambiental praticado no Brasil engloba os quatro processos gerais da indústria de petróleo e gás natural classificados pela Environmental Protection Agency (2000, p. 15) dos 
Estados Unidos: a exploração ou procura por formações rochosas associadas a depósitos petróleo ou gás natural, a produção para pesquisa (well development), a perfuração de um ou mais poços para testar a viabilidade econômica de produção do reservatório, a produção ou extração e separação do petróleo, gás natural, água e sólidos encontrados no reservatório e, finalmente, o abandono ou fechamento do poço e restauração do local quando a produção deixa se der economicamente viável.

Além de todos os documentos que devem ser apresentados como exigência do processo de licenciamento ambiental, o Ibama, por meio da Diretoria de Licenciamento Ambiental/Coordenadoria Geral de Petróleo e Gás, exige do empreendedor o cumprimento de medidas mitigadoras de impactos ambientais, entre as quais o Projeto de Controle da Poluição.

As diretrizes para a apresentação, implementação e elaboração de relatórios do Projeto de Controle da Poluição nos processos de licenciamento ambiental dos empreendimentos marítimos de exploração e produção de petróleo e gás encontram-se na Nota Técnica do Ibama. De acordo com esse documento, o Projeto de Controle da Poluição tem cinco objetivos fundamentais: gerar o mínimo possível de resíduos sólidos, efluentes líquidos e emissões atmosféricas; reciclar o máximo possível dos resíduos desembarcados; proceder à disposição final adequada, isto é, de acordo com as normas legais vigentes, de todos os resíduos desembarcados e não reciclados; buscar procedimentos que minimizem a poluição gerada pelas emissões atmosféricas e pelos resíduos sólidos e efluentes líquidos passíveis de descarte no mar, e aprimorar continuamente os procedimentos citados nos itens anteriores.

A partir dos dados apresentados até 2009 pelas empresas petrolíferas em seus Projetos de Controle da Poluição, o órgão federal ambiental competente, o Ibama, catalogou os resíduos sólidos gerados pela indústria do petróleo e gás, editando, dois anos depois, a Nota Técnica Ibama. A edição dessa norma foi uma antecipação aos resultados de uma pesquisa realizada pelo Instituto de Pesquisa Econômica Aplicada, da Secretaria de Assuntos Estratégicos da Presidência da República, sobre os resíduos gerados na indústria do petróleo, também com base nos Projetos de Controle da Poluição que seriam publicados em 2012.
De fato, a partir de 2010, com a entrada em vigor da Política Nacional de Resíduos Sólidos, além das exigências impostas a diferentes atividades econômicas, passaram a ter obrigações também o próprio Poder Público, como a de desenvolver os Planos de Resíduos Sólidos (nacional, estaduais e municipais), ação que implica, por sua vez, o diagnóstico da situação dos resíduos sólidos.

Na próxima seção serão detalhados os principais aspectos relacionados aos resíduos sólidos da indústria petrolífera, em particular aqueles indicados pela Nota Técnica Ibama.

\section{A produção de resíduos sólidos pela indústria petrolífera}

O texto da Nota Técnica do Ibama ressalta que, entre seus objetivos, estão acompanhar os indicadores de cada empreendimento, observar a gestão dos resíduos, efluentes e emissões, consolidar e disponibilizar as informações, publicamente, para a efetivação de um controle social das políticas públicas sobre as atividades licenciadas. Dessa forma, para a análise aqui proposta serão utilizados os dados apresentados nesse instrumento jurídico.

Antes, porém, faz-se necessário apresentar a divisão do fluxo das atividades de exploração e produção (E\&P) que consiste, segundo Koehler (2012, p. 12), em upstream - atividades ligadas à exploração e à produção em si (sísmica, perfuração e produção) e - downstream, atividades englobando o refino, distribuição e comercialização. Nesse artigo, em virtude da complexidade dessa cadeia de atividades, conforme discutido na Introdução, e de acordo com a disponibilidade dos dados previstos na Nota Técnica do Ibama, a análise tem como foco os resíduos sólidos gerados nas atividades upstream em campos marítimos (exploração offshore), onde estão concentradas $92,8 \%$ das reservas nacionais de petróleo.

Os principais processos geradores de resíduos sólidos das atividades de E\&P offshore upstream se dividem de acordo com o tipo de atividade, que pode ser de sísmica, de perfuração e de produção. Nas atividades de sísmica, os resíduos sólidos são gerados a partir do uso de lubrificantes, produtos de motores e equipamentos, além da própria ocupação humana nas instalações, que gerará 
resíduos ligados às atividades de hotelaria e escritório. Nas atividades de perfuração, os resíduos sólidos são gerados a partir de: fluidos de perfuração - base aquosa (descarte no mar), cascalhos (descarte no mar), fluidos de base não aquosa, cascalho contaminado, hotelaria/ acomodações e escritórios, lubrificantes/produtos de motores e equipamentos, soldagens/reparos mecânicos, produtos químicos/resíduos contaminados de óleo. E, enfim, para as atividades de produção, os resíduos são gerados a partir de: hotelaria/acomodações e escritórios, lubrificantes/produtos de motores e equipamentos, soldagens/reparos mecânicos, reparos em estrutura metálica/ chapeamento, produtos químicos/resíduos contaminados de óleo, processamento de óleo e gás, água produzida com descarte no mar (Koehler, 2012, p. 12).

No mapeamento apresentado pela Nota Técnica do Ibama, as atividades de E\&P produziram, apenas no ano de 2009, 44.437 toneladas (t) de resíduos sólidos, dentre os quais chamam atenção, pela grande quantidade de produção, os resíduos oleosos (16.002 t), os resíduos contaminados (5.630 t), os metais não contaminados (11.085 t) e os resíduos não passíveis de reciclagem (4.935 t), destacados em negrito na Tabela 1 .

TABELA 1 - Quantidades e tipos de resíduos sólidos produzidos.

\begin{tabular}{ll}
\hline Tipos de resíduos & Quantidade (t) \\
\hline 1 - Resíduos oleosos & $\mathbf{1 6 . 0 0 2 , 8 3}$ \\
2 - Resíduos contaminados & $\mathbf{5 . 6 3 0 , 2 8}$ \\
3 - Tambor / Bombona contaminado & 963,53 \\
4 - Lâmpada fluorescente & 26,14 \\
5 - Pilha e bateria & 129,62 \\
6 - Resíduo infectocontagioso & 22,61 \\
7 - Cartucho de impressão & 2,61 \\
8 - Lodo residual do esgoto tratado & 190,77 \\
9 - Resíduo alimentar desembarcado & 178,01 \\
10 - Madeira não contaminada & $1.861,78$ \\
11 - Vidro não contaminado & 177,46 \\
12 - Plástico não contaminado & 807,03 \\
13 - Papel/papelão não contaminado & 931,82 \\
$\mathbf{1 4}$ - Metal não contaminado & $\mathbf{1 1 . 0 8 5 , 1 3}$ \\
15 - Tambor / Bombona não contaminado & 188,85 \\
16 - Lata de alumínio & 70,67 \\
$\mathbf{1 7}$ - Resíduos não passíveis de reciclagem & $\mathbf{4 . 9 3 5 , 5 2}$ \\
18 - Borracha não contaminada & 41,44 \\
19 - Produtos Químicos & $1.146,03$ \\
20 - Óleo de cozinha & 4,68 \\
21 - Resíduos de plástico e borracha & 40,27 \\
Total & $\mathbf{4 4 . 4 3 7 , 0 8}$ \\
\hline
\end{tabular}

FONTE: Adaptado de Ibama (2011b, p. 10)
Do total de resíduos sólidos gerados pelas atividades de E\&P, o Ibama recorreu à classificação resíduos sólidos estabelecida pela Associação Brasileira de Normas Técnicas (NBR 10004:2004) para realizar o seguinte enquadramento, distribuído de forma percentual: $54,3 \%$ (24.129,33 t) de resíduos perigosos (Classe I); 27,9\% (12.397,94 t) de resíduos não inertes e não perigosos (Classe IIA); e 17,8\% (7.909,80 t) de resíduos inertes e não perigosos (Classe IIB) (Ibama, 2011b, p. 9, 17, 19). Para os maiores volumes de resíduos produzidos pela E\&P petrolífera tem-se, especificamente, a seguinte distribuição: resíduos oleosos (Classe I); resíduos contaminados (Classe I); resíduos não passíveis de reciclagem (Classe IIA); e metal não contaminado (Classe IIB) (Ibama, 2011b, p. 17-18).

Os resíduos provenientes dos fluidos de perfuração são um tipo que deve ter seu monitoramento controlado. A base desse fluido, que tem como principal função a de carrear o cascalho até a superfície, pode ser aquosa ou não aquosa, sendo esta última potencialmente poluidora do ambiente, devendo ser levada à terra para tratamento. A quantidade e a destinação desses tipos de resíduos não são contempladas nos relatórios de acompanhamento dos Projetos de Controle da Poluição. No texto da Nota Técnica do Ibama, o órgão público reconhece que ainda lhe falta uma norma para realizar um procedimento "mais robusto para a gestão destas informações"; contudo, afirma que já está providenciando norma específica para sanar esse problema (Ibama, 2011b, p. 24, 36), sem ter sido editada até outubro de 2014.

Em relação às formas de destinação final dos resíduos sólidos, estão previstos na Nota Técnica Ibama: a devolução ao fabricante, o reuso, a reciclagem, o recondicionamento, o re-refino, o coprocessamento, a descontaminação, o aterro sanitário, o aterro industrial, a incineração em terra, a estação de tratamento, o blend de resíduos e a compostagem. Para os maiores volumes de resíduos sólidos produzidos, os principais destinos foram dados de acordo com a Tabela 2, distribuídos de forma percentual.

Da análise dos percentuais referidos na Tabela 2, é possível constatar que as principais formas de destinação final das atividades de E\&P do petróleo são o re-refino, o coprocessamento e a estação de tratamento. $\mathrm{O}$ rastreamento das principais formas de destinação 
TABELA 2 - Principais percentuais das formas de destinação final dos resíduos.

\begin{tabular}{|c|c|c|c|c|c|c|c|}
\hline \multirow[b]{2}{*}{ Tipos de Resíduos } & \multicolumn{7}{|c|}{ Destinação final } \\
\hline & Reuso & Reciclagem & Re-Refino & $\begin{array}{l}\text { Coproces- } \\
\text { samento }\end{array}$ & $\begin{array}{c}\text { Aterro } \\
\text { sanitário }\end{array}$ & $\begin{array}{c}\text { Aterro } \\
\text { industrial }\end{array}$ & $\begin{array}{l}\text { Estação de } \\
\text { tratamento }\end{array}$ \\
\hline Resíduos oleosos & $0,02 \%$ & $0,30 \%$ & $38,55 \%$ & $10,57 \%$ & $0,01 \%$ & $2,12 \%$ & $46,58 \%$ \\
\hline Resíduos contaminados & $0,02 \%$ & $2,70 \%$ & $0,24 \%$ & $75,21 \%$ & $0,24 \%$ & $18,90 \%$ & $0 \%$ \\
\hline Metal não contaminado & $2,63 \%$ & $96,37 \%$ & $0 \%$ & $0,07 \%$ & $0,86 \%$ & $0 \%$ & $0 \%$ \\
\hline $\begin{array}{l}\text { Resíduos não passíveis de } \\
\text { reciclagem }\end{array}$ & $0,19 \%$ & $9,80 \%$ & $0 \%$ & $6,61 \%$ & $34,46 \%$ & $47,73 \%$ & $0 \%$ \\
\hline
\end{tabular}

FONTE: Adaptado de Ibama (2011b, p. 27).

será importante para o cumprimento de uma inovação conceitual incorporada à Política Nacional de Resíduos Sólidos: a responsabilidade compartilhada.

O texto da Nota Técnica Ibama avalia que os dados apresentados subsidiarão o planejamento e a execução das ações de acompanhamento dos PCP, além de monitorar os resultados de controle da poluição e efeitos do crescimento de atividades em certas regiões no decorrer do tempo. Além disso, o órgão ambiental, no âmbito da sua Coordenadoria Geral de Petróleo e Gás, prevê um aumento da geração de resíduos, com seus respectivos impactos negativos em virtude da produção do pré-sal. Conclui, ainda, ressaltando o papel da própria Nota Técnica Ibama em subsidiar a implementação da Política Nacional de Resíduos Sólidos, mediante contribuição para a elaboração do Plano Nacional de Resíduos Sólidos.

A partir deste levantamento, a seguir serão apontadas as fragilidades da PNRS, quando da sua aplicação para a indústria do petróleo, identificadas com base na leitura conjunta da Política Nacional de Meio Ambiente, da Política Nacional de Resíduos Sólidos e da Nota Técnica do Ibama.

\section{Aplicação da PNRS na indústria petrolífera}

De acordo com Ministério do Meio Ambiente (MMA, 2012), as discussões sobre a criação da PNRS tiveram início em 2004, quando o governo federal instituiu um grupo interministerial para elaborar uma proposta de lei que foi debatida em todos os ministérios e apresentada publicamente em 2005, durante um Seminário promovido pelos Ministérios do Meio Ambiente, das Cidades e da
Saúde, além da Funasa e da Caixa Econômica Federal. Após as inúmeras discussões que se sucederam, o projeto de lei foi enviado para o Congresso Nacional em 2007 e aprovado com pequenas alterações. Politicamente, a construção da proposta da PNRS foi capitaneada pela Secretaria de Recursos Hídricos e Ambiente Urbano do Ministério do Meio Ambiente. A liderança dessa Secretaria refletiu-se no texto que instituiu a política pública, aguardada há muito tempo por profissionais das áreas das ciências ambientais e do Terceiro Setor, pois se observa a ocorrência de inúmeros direcionamentos para a produção de resíduos no meio urbano, como a preocupação em integrar nas ações governamentais a categoria dos catadores de materiais reutilizáveis e recicláveis, chegando mesmo a citá-los textualmente doze vezes. Reforçando essa constatação, o sítio eletrônico do Ministério do Meio Ambiente ressalta positivamente que foi numa exposição de catadores em 2010 que o presidente da República, àquela época, assinou o decreto regulamentador da PNRS (Decreto $\left.n^{\circ} 7.404 / 2010\right)$. Paradoxalmente, percebe-se certa negligência no tocante à produção de resíduos industriais, com a PNRS deixando de estabelecer uma classificação mais consistente dos resíduos quanto à periculosidade, limitando-se a estabelecer um conceito amplo de resíduo perigoso (art. 13, II, PNRS). Em resumo, a PNRS está ancorada na valorização da área urbana, principalmente no que tange à produção dos resíduos urbanos, e em uma notável ausência de detalhamento sobre os resíduos industriais, os principais causadores de impactos ambientais.

A PNRS tem como objetivo criar uma estrutura institucional-legal para um melhor gerenciamento dos resíduos sólidos produzidos no Brasil. Para tanto, no caso 
específico do petróleo, conta com a aplicação conjunta da Lei 9.966/00, que dispõe sobre a prevenção, o controle e a fiscalização da poluição causada por lançamento de óleo e outras substâncias nocivas ou perigosas em águas sob a jurisdição nacional. A lei 9.966/00, doravante, lei da poluição marinha, expressamente citada na PNRS, abrange, especialmente, as emissões ocorridas em embarcações nacionais, portos, instalações portuárias, dutos, plataformas e instalações, partes físicas integrantes da indústria petrolífera.

A importância da análise da indústria petrolífera deve-se ao fato de os resíduos gerados em sua cadeia produtiva serem classificados, consoante os dispositivos da PNRS, como resíduos industriais perigosos (art. 13, I, f). Ademais, possuem características de inflamabilidade, corrosividade, reatividade e risco significativo à saúde pública e à qualidade ambiental (art. 13, II, a). Com relação à periculosidade, a PNRS se limita a apresentar um conceito muito abrangente de "resíduos perigosos" como sendo "aqueles que, em razão de suas características de inflamabilidade, corrosividade, reatividade, toxicidade, patogenicidade, carcinogenicidade, teratogenicidade e mutagenicidade, apresentam significativo risco à saúde pública ou à qualidade ambiental, de acordo com lei, regulamento ou norma técnica" (art. 13, II, a).

Essa definição aberta requer, para a compreensão de resíduos sólidos perigosos, a complementação de elementos específicos em outros dispositivos ou normas técnicas. A Nota Técnica Ibama utilizou-se da classificação encontrada na norma da Associação Brasileira de Normas Técnicas (NBR 10004:2004), na qual os resíduos perigosos estão organizados em três Classes: Classe I, Classe IIA e Classe IIB. Contudo, essa classificação não é a mesma adotada no ordenamento vigente, inclusive indicado na PNRS, qual seja, a lei da poluição marinha. Assim sendo, pode haver uma incompatibilidade na interpretação e na aplicação do conceito de resíduos perigosos, uma vez que a lei da poluição marinha, ao conceituar substância nociva ou perigosa, adota parâmetro diferente de classificação, organizando os resíduos em quatro categorias de riscos à saúde humana e ao ecossistema aquático: A (alto risco); B (risco médio); C (risco moderado) e D (risco baixo). Logo, faz-se necessária a definição da classificação de resíduos perigosos para que a atuação dos órgãos de fiscalização da qualidade ambiental ocorra segundo o estrito cumprimento do ordenamento jurídico, em atenção ao princípio da legalidade. Sob essa perspectiva, é preciso haver a compatibilização entre a PNRS e a lei da poluição marinha, aplicando-se a classificação segundo os riscos quando da interpretação dos resíduos perigosos.

Para os resíduos sólidos industriais e perigosos, a PNRS exige que seja elaborado um Plano de Gerenciamento de Resíduos Sólidos (art. 20, I e II, a). Esse Plano tem que conter, minimamente, nove itens: (1) a descrição do empreendimento ou atividade; (2) o diagnóstico dos resíduos sólidos (origem, volume, caracterização); (3) explicitação dos responsáveis por cada etapa do gerenciamento; (4) definição dos procedimentos operacionais sob responsabilidade do gerador; (5) identificação das soluções consorciadas ou compartilhadas com outros geradores; (6) ações preventivas e corretivas em casos de erros ou acidentes; (7) metas e procedimentos para minimizar a geração de resíduos, reutilização e reciclagem; (8) medidas saneadoras dos passivos ambientais relacionados aos resíduos sólidos; (9) periodicidade da revisão do plano. Com relação à indústria do petróleo, a lei da poluição marinha prevê que os operadores de plataformas elaborem um manual de procedimento interno para o gerenciamento de riscos de poluição e gestão dos resíduos gerados pela movimentação e armazenamento de óleo ou substâncias nocivas ou perigosas. Além do manual, também deverão ser elaborados planos de emergência individuais para combater a poluição por óleo e substâncias nocivas ou perigosas $\left(\operatorname{art} .7^{\circ}\right)$. O manual e os planos de emergência deverão ser aprovados pelo órgão ambiental competente. Dessa forma, parece razoável apontar o manual de procedimento interno e os planos de emergência como esboços de um plano de gerenciamento de resíduos sólidos, configurando-se em uma forma de aplicação do princípio da prevenção.

A elaboração, a implementação, a operacionalização e o monitoramento do plano terão um responsável técnico habilitado, a quem recai a obrigação de manter o plano atualizado e disponível aos órgãos do Sistema Nacional de Meio Ambiente. A PNRS dispõe que o plano de gerenciamento de resíduos sólidos é parte integrante do processo de licenciamento ambiental da atividade produtiva. Entretanto, não especifica de que forma e não dispõe nada acerca de um possível enquadramento das 
atividades geradoras de resíduos. Tampouco faz referência à apresentação de um plano de gerenciamento de resíduos para os empreendimentos em operação, com a devida licença ambiental, antes da entrada da PNRS em 2010. Esta omissão legislativa é relevante, considerando-se o caso da indústria do petróleo, onde a validade da licença de operação pode chegar a dez anos. Assim, por exemplo, como resolver a situação de uma licença de operação emitida pouco antes da entrada em vigor da exigência de apresentação do plano? Pode ocorrer que durante o lapso temporal de quase uma década não se tenha o plano de gerenciamento, que é um importante instrumento para avaliar o gerenciamento dos resíduos sólidos perigosos daquela atividade.

Para a política pública nacional de resíduos sólidos, o gerador de resíduos perigosos é quem possui a responsabilidade de apresentar um plano de gerenciamento de resíduos perigosos, que poderá estar contido no plano de gerenciamento de resíduos. Ainda como obrigação, o gerador deverá manter o registro atualizado e facilmente acessível sobre os procedimentos do plano, informar anualmente quantidade, natureza e destinação temporária ou final dos resíduos, informar sobre a ocorrência de acidentes ou outros sinistros e adotar medidas para reduzir o volume e a periculosidade dos resíduos. Em relação a esse aspecto, faz-se necessária uma crítica quanto à proposta da lei que institui essa política pública em reduzir a periculosidade de resíduos perigosos. Isso porque a característica de periculosidade é inerente ao resíduo perigoso, logo, o que se deveria exigir é a adoção de medidas para que seja reduzida a exposição ao risco proveniente do resíduo perigoso. Nesse sentido, é inquestionável que a definição de um critério único de classificação de resíduos sólidos, a ser aplicado na interpretação das normas ambientais, configura um dos elementos basilares para a efetividade da PNRS.

Dentro das diretrizes aplicáveis aos resíduos sólidos, a PNRS dedicou um capítulo específico para os resíduos perigosos (Capítulo IV, Título III, arts. 37 a 41), que será aqui analisado tendo em vista que, de acordo com a Nota Técnica Ibama, a maior parte da produção de resíduos da indústria do petróleo se enquadra nessa categoria.

No artigo 37 da PNRS, o texto legal prevê uma situação para empreendimentos que ainda não estão instalados ou operando, pois os geradores de resíduos perigosos " $[\ldots]$ somente podem ser autorizados ou licenciados pelas autoridades competentes se o responsável comprovar, no mínimo, capacidade técnica e econômica [...]" para gerenciar esses resíduos. Assim, resta uma importante lacuna no tocante aos empreendimentos que já se encontravam em operação quando da promulgação da lei.

No caso da indústria do petróleo, a lei da poluição marinha prevê que as plataformas e instalações de apoio deverão ter instalações ou meios adequados para receber e tratar os resíduos $\left(\operatorname{art} .5^{\circ}\right)$.

Das constatações feitas aqui, ainda que fujam ao foco direcionado para a indústria upstream, por desdobramento lógico, faz-se necessária uma revisão do artigo 33 da PNRS, aquele que trata da logística reversa. O reconhecimento dos resíduos da indústria petrolífera como perigosos, dentro de uma concepção ampla de toda a cadeia produtiva, enseja a sua incorporação não como uma mera menção a "óleos lubrificantes, seus resíduos e embalagens", mas, abarcando todos os derivados de petróleo, seus resíduos e embalagens.

Uma inovação interessante da PNRS é a possibilidade, no âmbito do processo de licenciamento ambiental de produtos perigosos, de contratação de seguro de responsabilidade civil por danos causados ao meio ambiente ou à saúde pública. Todavia, as regras de cobertura e limites máximos de contratação ficam condicionados às regras estabelecidas pelo Conselho Nacional de Seguros Privados (art. 67, Decreto $n^{\circ} 7.404 / 10$ ).

Outro ponto importante da PNRS a ser ressaltado é a descontaminação das “áreas órfãs” pelo Poder Público. Cabe ao Estado a responsabilidade pela descontaminação das áreas em que não houver meios para se determinar o agente poluidor. Contudo, sobre o termo genérico "Poder Público" a PNRS não delimitou exatamente qual esfera de poder, federal, estadual ou municipal, será responsável por essa ação, nem delimitou critérios para o estabelecimento de divisões de responsabilidade. Dessa forma, cabe a crítica feita por Antunes (2008, p. 80) de que a competência comum é uma "verdadeira 'armadilha', visto que, na prática, a atribuição de todos acaba se transformando na atribuição de ninguém”, e o ambiente contaminado pode continuar nesse estado por anos até que se determine a competência de quem deverá descontaminá-lo. 
Com base no recorte proposto, o texto da PNRS não consegue atingir de forma satisfatória as dimensões da produção nacional de resíduos sólidos. Assim sendo, confirma-se a hipótese proposta, segundo a qual a PNRS não abrange todos os tipos de atividades industriais, em especial a indústria do petróleo. Percebe-se que sua construção foi setorizada, sendo direcionada de forma significativa para a produção de resíduos sólidos urbanos. Particularmente no tocante à sua aplicação na indústria do petróleo brasileira, apesar de tantos mecanismos criados para que sua efetivação fosse plena, foram ressaltados os diversos dispositivos em que a PNRS foi omissa. Face ao cenário de expansão da indústria petrolífera nacional com o pré-sal e, consequentemente, do aumento na geração de resíduos sólidos perigosos, esta ausência de regulamentação específica para os resíduos sólidos da indústria petrolífera configura uma situação jurídica que requer uma revisão da PNRS e a ampliação da discussão técnico-científica sobre os resíduos sólidos da indústria petrolífera, em uma perspectiva holística, em consonância com as diretrizes da política ambiental brasileira.

Importa, por fim, destacar que a análise feita nesta seção não pretendeu esgotar o tema, mas trazer ao debate essas e outras questões inerentes ao processo regulatório da indústria petrolífera, como os resíduos gerados durante a etapa de abandono ou descomissionamento da atividade (Teixeira \& Machado, 2012), fase pouco abordada em estudos nacionais e com grande potencial gerador de resíduos e de impactos ambientais.

\section{Considerações finais}

Em virtude da relevância atual da indústria petrolífera no país, em franca expansão com o pré-sal, optou-se por analisar este setor produtivo, sobretudo devido aos impactos reais e potenciais para o meio ambiente e a saúde relacionados aos resíduos gerados em toda a cadeia produtiva, que abrange a extração do petróleo e do gás natural, além daqueles inerentes ao seu beneficiamento e à comercialização de seus derivados.

Da conjugação de elementos teóricos e normativos, destacou-se a imposição constitucional do modelo de desenvolvimento sustentável como norteador das políticas nacionais, particularmente aquelas que versem sobre meio ambiente.

Da análise da Política Nacional de Resíduos Sólidos, sob o enfoque da sustentabilidade, foi identificado um amplo espectro de resíduos perigosos negligenciados no texto legal. Foi institucionalizada uma política pública que não incorpora a concepção holística de meio ambiente e não traduz a visão transversal da questão ambiental. Ao contrário, apresenta lacunas que contrariam os desígnios constitucionais, precisamente em contribuir para o "desenvolvimento nacional qualificado por um crescimento econômico fundado sobre a justiça social, a preservação ambiental e a responsabilidade intergeracional" (Machado \& Godinho, 2012, p. 139). Seu direcionamento foi para a produção dos resíduos sólidos urbanos, restando, portanto, omissões agudas na regulamentação dos resíduos perigosos e, por consequência, na aplicação dos princípios do desenvolvimento sustentável, da prevenção, do poluidor-pagador e da equidade intergeracional.

Outra crítica à PNRS é a obrigatoriedade de apresentação de um Plano de Gerenciamento de Resíduos Sólidos Industriais por parte do poluidor, como parte integrante do processo de licenciamento, mas não prevê de que forma, em que fase do licenciamento e para quais tipos de licença. Além disso, também não se pronuncia quanto a uma adaptação ou não das atividades que já estejam licenciadas, abrindo uma oportunidade para o não enquadramento dos empreendimentos poluentes pelo tempo de validade da licença ambiental.

Muitas outras críticas podem ser detalhadas, porque existem outras importantes questões que precisam de um maior aprofundamento, a exemplo da destinação final de resíduos e da responsabilidade compartilhada, assuntos que demandam trabalhos futuros. Contudo, ao longo desse artigo, os esforços teóricos e interpretativos realizados se voltaram para o fortalecimento dos instrumentos, objetivos e princípios da Política Nacional de Meio Ambiente, de maneira geral, ressaltando a persistente visão fragmentada da questão ambiental nos dispositivos específicos, como a Política Nacional de Resíduos Sólidos.

Por fim, destaca-se aqui que as reflexões e críticas apresentadas são fruto do reconhecimento não apenas da possibilidade de incorporação do modelo de desenvol- 
vimento sustentável pelas políticas públicas nacionais, mas, sobretudo, de que essa se faz por uma exigência constitucional, ética e humanitária. Como nos lembra a obra Desenvolvimento sustentável para o Antropoceno: um olhar panorâmico (Machado, 2014, p. 288), se quisermos garantir a perenidade de nossas vidas na terra

\section{Referências}

ANP - Agência Nacional do Petróleo, Gás Natural e Biocombustíveis. Boletim da produção de petróleo e gás natural dezembro 2014. Disponível em: <http://www.anp.gov. br/?pg=73557>. Acesso em: fev. 2015.

Antunes, P. B. Direito Ambiental. Rio de Janeiro: Lumen Juris, 2008.

Bucci, M. P. A Comissão Brundtland e o conceito de Desenvolvimento Sustentável. In: Derani, C.; Costa, J. (Orgs.). Direito Ambiental Internacional. Santos: Leopoldianum, 2001. p. 50-63.

Carneiro, E. J. Política ambiental e a ideologia do desenvolvimento sustentável. In: Zhouri, A.; Laschefski, K.; Pereira, D. B. (Orgs.). A insustentável leveza da política ambiental: desenvolvimento e conflitos socioambientais. Belo Horizonte: Autêntica, 2005. p. 27-47.

Carvalho, D. W. Regulação constitucional e risco ambiental. Revista Brasileira de Direito Constitucional, 12, 13-31, 2008. Disponível em: <http://www.esdc.com.br/RBDC/RBDC-12/ RBDC-12-013-Delton_Winter_de_Carvalho_(risco_ambiental).pdf $>$.

Derani, C. Direito ambiental econômico. São Paulo: Max Limonad, 2001.

Environmental Protection Agency. Profile of the Oil and Gas Extraction Industry. Washington: EPA, 2000.

Farzin, Y. H. Can an exhaustible resource economy be sustainable? Social Science Research Network, 2002. Disponível em: <http://papers.ssrn.com/sol3/papers.cfm?abstract_ id $=317933>$.

IBAMA. Ibama informa sobre o Cadastro Nacional de Operadores de Resíduos Perigosos. Brasília: Ibama, 2011a. Disponível em: <http://www.ibama.gov.br/publicadas/ ibama-informa-sobre-o-cadastro-nacional-de-operadores-de-residuos-perigosos>. Acesso em: nov. 2012. brasilis, é preciso deixar de tolerar danos ambientais por conta de decisões baseadas unicamente em critérios econômicos. As atividades industriais do Brasil podem ser desenvolvidas sem degradação ambiental. É preciso agir de forma responsável em um mundo comum que contemple a todos em direitos e deveres.

IBAMA. Nota Técnica Ibama/Dilic/CGPEG n.07/2011. Brasília: Ibama, 2011b.

Jacques, R. J. S.; Bento, F. M.; Antoniolli, Z. I.; Camargo, F. A. O. Biorremediação de solos contaminados com hidrocarbonetos aromáticos policíclicos. Ciência Rural, 37, 1192-1201, 2007. doi: 10.1590/S0103-84782007000400049.

Koehler, P. H. W. Diagnóstico da situação atual dos resíduos sólidos das atividades de exploração e produção de petróleo e gás natural nas bacias sedimentares maritimas do Brasil. Brasília: IPEA, 2012. 40 p. Relatório técnico.

Lenzi, C. L. Sociologia ambiental: risco e sustentabilidade na modernidade. Bauru: Edusc, 2006.

Machado, C. J. S. Introdução. Inter-relações e tensões entre o global e o local. In: Machado, C. J. S. (Org.). Ciências, políticas públicas e sociedade sustentável. Rio de Janeiro: E-papers, 2012. p. 11-42.

Machado, C. J. S. Desenvolvimento sustentável para o Antropoceno: um olhar panorâmico. Rio de Janeiro: E-papers, 2014.

Machado, C. J. S.; Vilani, R. M. Aspectos conceituais do licenciamento ambiental na conservação de recursos naturais não renováveis - exploração de petróleo e gás natural no Brasil. Revista de Informação Legislativa, 188, 143-152, 2010.

Machado, C. J. S.; Godinho, R. S. Acesso à diversidade biológica e aos conhecimentos tradicionais associados. In: Machado, C. J. S. (Org.). Ciências, politicas públicas e sociedade sustentável. Rio de Janeiro: E-papers, 2012. p. 103-148.

Machado, C. J. S.; Vilani, R. M.; Godinho, R. S. Royalties do petróleo e política de preservação da biodiversidade. In: Machado, C. J. S. (Org.). Ciências, políticas públicas e sociedade sustentável. Rio de Janeiro: E-papers, 2012. p.149-190.

Machado, P. A. L. Direito Ambiental brasileiro. São Paulo: Malheiros, 2010. 
Machado, P. A. L. Princípios da política nacional de resíduos sólidos. Revista do Tribunal Regional Federal da $1^{a}$ Região, 24, 25-33, 2012.

Mendes, G. F.; Forster Júnior, J. Manual de redação da Presidência da República. Brasília: Presidência da República, 2002.

Milaré, É. Direito do ambiente. São Paulo: RT, 2000.

MMA - Ministério do Meio Ambiente. Política Nacional de Resíduos Sólidos. Brasília: Ministério do Meio Ambiente. Disponível em: <http://www.mma.gov.br/cidades-sustentaveis/ residuos-solidos/politica-nacional-de-residuos-solidos/contextos-e-principais-aspectos>. Acesso em: nov. 2012.

Sisinno, C. L. S.; Pereira Netto, A. D.; Rego, E. C. P.; Lima, G. S. V. Hidrocarbonetos policíclicos aromáticos em resíduos sólidos industriais: uma avaliação preliminar do risco potencial de contaminação ambiental e humana em áreas de disposição de resíduos. Cadernos de Saúde Pública, 19, 671-676, 2003. doi: 10.1590/S0102-311X2003000200035.
Teixeira, B. M.; Machado, C. J. S. Marco regulatório brasileiro do processo de descomissionamento ambiental da indústria do petróleo. Revista de Informação Legislativa, 196, 183-203, 2012.

Tolmasquim, M. Perspectivas e planejamento do setor energético no Brasil. Estudos Avançados, 26, 247-260, 2012. doi: 10.1590/S0103-40142012000100017.

United Nations. Our Common Future. Report of the World Commission on Environment and Development. 96th plenary meeting, 11 dec. 1987. Disponível em: <http://www.un.org/ documents/ga/res/42/ares42-187.htm>. Acesso em: out. 2014.

Veiga, J. E. Desenvolvimento sustentável: o desafio do século XXI. Rio de Janeiro: Garamond, 2006.

Vilani, R. M.; Machado, C. J. S. A competência da União para a elaboração de "plano nacional das atividades de exploração de petróleo e gás natural" no Brasil. Ambiente \& Sociedade, 13, 187-206, 2010. doi: 10.1590/S1414-753X2010000100012. 